\title{
Asma infantil sob a óptica materna: uma abordagem qualitativa
}

Recebido em: 12/01/2011

Aceito em: 14/04/2011

\author{
Conceição de Maria de Albuquerque ${ }^{1}$ \\ Dárcia Pinheiro Nogueira² \\ Samyra Rodrigues Maciel Medina Guimarães ${ }^{3}$ \\ Caroline Soares Nobre ${ }^{4}$ \\ Sayonara Aquino de Almeida Tavares ${ }^{5}$
}

Objetivou-se conhecer a percepção materna acerca da vivência com o filho asmático e investigar o conhecimento das mães sobre o tratamento da asma. Estudo exploratório qualitativo realizado na Unidade de Sanitária César Cals. A coleta de dados ocorreu de abril a maio de 2009, com 20 participantes. Efetuou-se a transcrição dos relatos por análise dos dados, logo emergindo as categorias: conhecimento aparente da patologia; benefícios quanto aos gastos com medicamentos; "mudou muito, porque ela só vivia internada"; "pratica esporte e não se cansa mais". Portanto, o conhecimento da população acerca do programa advém das orientações profissionais, vislumbrando as políticas de saúde da criança.

Descritores: Asma, Enfermagem em Saúde Comunitária, Criança.

\section{Childhood asthma under maternal approach: a qualitative approach}

Here we intend to learn about the maternal perception about the life with an asthmatic child and investigate the mothers' knowledge about the treatment of asthma. This is an exploratory and qualitative study carried out by the Sanitary César Cals. The data collection occurred in April/May 2009, among twenty participants. The reports transcription were made by data analysis, soon emerging these categories: apparent knowledge of the pathology; benefits regarding drug spending; she's changed a lot, because she lived only in hospital; practicing sports and not get tired anymore. So people's knowledge about the program comes from professional advice, thus catching a glimpse of the politics of child health.

Descriptors: Asthma, Community Health Nursing, Child.

\section{El asma infantil en la perspectiva de la madre: una aproximación cualitativa}

Tuvo como objetivo conocer la percepción materna del niño que vive con asma e investigar los conocimientos de las madres sobre el tratamiento del asma. Estudio exploratorio cualitativo se llevó a cabo en los Cals Sanitaria César. La recogida de datos tuvo lugar en abril/mayo de 2009 con veinte participantes. La transcripción fue hecha por el análisis de los datos, luego emergiendo las categorías: la patología del conocimiento aparente, los beneficios sobre los gastos de medicamentos, ha cambiado mucho, porque sólo se vivía en el hospital, practica deporte y no se cansan más. Por lo tanto el conocimiento de la gente sobre el programa proviene de un asesoramiento profesional, y de la política de la salud infantil.

Descriptores: Asma, Enfermería em Salud Comunitaria, Niño.

\section{INTRODUÇÃO}

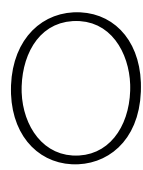
sentido etimológico da palavra asma advém do grego asthma, que significa sufocante, arquejante. Conhecida desde a antiguidade por acometer indivíduos de todas as idades, diferentes níveis sociais e culturais, com graus variados de gravidade e frequência, é considerada um entrave presente nas políticas públicas em saúde infantil. Apreciada como uma patologia inflamatória crônica, caracteriza-se por hiper-responsividade das vias aéreas inferiores e limitação variável ao fluxo de oxigênio, manifestandose por episódios recorrentes de sibilância e dispneia ${ }^{(1,2)}$.
Cerca de $10 \%$ da população mundial é afetada pela asma, configurando-a como sério enigma de saúde pública. Tem como característica extrema variabilidade, tanto de doente para doente quanto de momentos diferentes no mesmo doente ${ }^{(3,4)}$.

No Brasil, ocorreram em média de 330 mil internações por asma em 2004, constituindo-se a terceira causa de hospitalizações pelo Sistema Único de Saúde (SUS). Dessas, a Região Nordeste é responsável por $43,6 \%$. Com relação a essa região, o Ceará conta com $15 \%$ das internações ${ }^{(5)}$.

1 Enfermeira. Mestre em Educação em Saúde pela Universidade de Fortaleza - Unifor. Docente do curso de Enfermagem da Universidade de Fortaleza. Enfermeira Assistencialista do Hospital Geral de Fortaleza - HGF e do Hospital Distrital Gonzaga Mota de Messejana.

2 Enfermeira graduada pela Universidade de Fortaleza.

3 Enfermeira graduada pela Universidade de Fortaleza.

4 Acadêmica do nono semestre do curso de Enfermagem pela Universidade de Fortaleza, Bolsista Pibic/CNPq. Membro do Núcleo de Pesquisa e Estudo em Saúde da Criança

- Nupesc/Unifor/CNPq.

5 Discente do nono semestre do curso de Enfermagem pela Universidade de Fortaleza, Bolsista Probic/FEQ. Membro do Núcleo de Pesquisa e Estudo em Saúde da Criança

- Nupesc/Unifor/CNPq. 
A fase 3 do International Study of Asthma and Allergies in Childhood (Isaac), realizada em 21 centros de 20 cidades brasileiras, distribuídas nas cinco regiões do país, ressaltou a prevalência média de $24,3 \%$ de asma ativa entre escolares de 6 a 7 anos e 19\% entre adolescentes de 13 a 14 anos. As taxas de prevalência de asma e doenças alérgicas mais elevadas foram observadas nos centros das Regiões Norte e Nordeste, exceção feita à de asma, que igualmente foi observada na Região Sul(6).

A criança é contemplada sob uma visão holística, como ser humano em desenvolvimento. Os direitos assegurados poderiam estar submetidos em um único, ou seja, a saúde. Isso pode ser justificado quando se considera saúde como complemento para o bem-estar físico, mental e social proposto pela Organização Mundial de Saúde (OMS). Daí a relevância do incentivo "precoce" à criança - precoce no sentido de atuar desde cedo e de manter o incentivo por toda a infância e a vida, pois é evidente que o sujeito, quando adulto, é consequência do que foi quando criança $^{(7)}$.

O Ministério da Saúde associou-se à Sociedade Brasileira de Pneumologia e Tisiologia (SBPT) e à Sociedade Brasileira de Pediatria (SBP), oficializando, em 1999, um acordo com diretrizes para a criação do Plano Nacional de Controle da Asma (PNCA). Foram criados, então, alguns programas de controle e atenção à asma, gerando experiências acumuladas de tratamento multiprofissional, controle da doença, redução da morbidade e da procura a serviços de urgência ${ }^{(8)}$.

Destaca-se que, em 2001, foi encaminhada ao Ministério da Saúde a Carta de Salvador, que alertava para a urgência da implantação definitiva do PNCA. Ocorreu um envolvimento governamental em 2003, inicialmente com o financiamento de medicamentos para asma grave. A partir de 2005, houve a aquisição de medicamentos para asma leve e moderada (portaria GM 2084), tendo os programas de asma como objetivo central no desenvolvimento dessa política ${ }^{(9)}$.

A apreciação dos programas brasileiros que oferecem experiência no manejo da asma demonstrou que os profissionais de enfermagem se destacam pela relevância no desempenho de funções nessa malha. O número dos envolvidos com o tratamento da asma foi superior ao de médicos generalistas, inclusive na média de consultas/mês por programa ${ }^{(10)}$.

Um aspecto questionado relaciona-se à constância das recidivas das crianças com o mesmo quadro. Assim, podese entender que um dos pilares da prevenção e do controle da asma diz respeito ao processo educativo, realizado pela assistência de enfermagem.

Considera-se a enfermagem, em especial o enfermeiro, como participante desse cenário, visto que as ações educativas são imprescindíveis para o estabelecimento do cuidado à saúde. Diante do exposto, objetivou-se conhecer a percepção materna acerca da vivência com o filho portador de asma e investigar o conhecimento das mães sobre o tratamento da asma infantil.

\section{METODOLOGIA}

Estudo exploratório com abordagem qualitativa, envolve-se com o universo de significados, motivos, aspirações, crenças, valores e atitudes, o que corresponde ao espaço mais profundo das relações, dos processos e dos fenômenos que não podem ser reduzidos à operacionalização de variáveis ${ }^{(11)}$

A pesquisa ocorreu na Unidade Sanitária César Cals de Oliveira, pertencente à Secretaria de Saúde do Estado do Ceará - Sesa. A coordenação da instituição foi informada do interesse dos autores por meio de ofício assinado, que permitiu sua efetivação.

Participaram 20 mães de crianças com diagnóstico médico confirmado de asma na faixa etária de 0 a 11 anos e 11 meses, que integram, juntamente com os filhos, o grupo de crianças asmáticas. Para a inclusão na pesquisa, utilizaram-se como critérios: o(a) filho(a) cadastrado(a) no programa de asma infantil da instituição, considerando a faixa etária citada; a mãe aceitar participar do estudo espontaneamente; e que não tenha algum distúrbio neurológico. Então elas assinaram o Termo de Consentimento Livre Esclarecido.

A coleta dos dados ocorreu de abril a maio de 2009. O primeiro contato das pesquisadoras com as participantes aconteceu na sala de acolhimento da instituição por meio da observação não participante. A segunda técnica utilizada ocorreu mediante a entrevista semiestruturada.

A análise dos dados efetuou-se após a transcrição na íntegra dos relatos. Posteriormente, aconteceram leituras flutuantes e aprofundadas, quando os dados foram organizados em grupos temáticos e em seguida em categorias empíricas embasadas na literatura pertinente ${ }^{(11)}$.

O estudo foi submetido ao Comitê de Ética em Pesquisa da Universidade de Fortaleza (Unifor) e aprovado sob o parecer $n^{\circ}$ $017 / 2009$. Atentou-se, portanto ao que preconiza a resolução $n^{\circ}$ 196/96 do Conselho Nacional de Saúde - Ministério da Saúde ${ }^{(12)}$, que regulamenta a pesquisa envolvendo seres humanos. Respeitaram-se os aspectos éticos e legais e incorporaram-se os princípios éticos da beneficência, o respeito à dignidade humana (autonomia), a justiça e a equidade.

\section{RESULTADOS}

Entre as 20 mães participantes, 12 declaram ser casadas, duas separadas e seis solteiras. No tocante à renda familiar, quatro ganhavam renda inferior a um salário mínimo, 15 ganhavam de um salário mínimo a dois salários e uma delas afirmou ganhar quatro salários mínimos. Quanto à escolaridade, duas são analfabetas e 18 são alfabetizadas, entre as quais cinco conseguiram concluir o ensino fundamental. 
Após leitura em busca de validação dos dados, mediante descrição cuidadosa das entrevistas e por meio de agrupamento, descrição, documentação e classificação das falas, foram identificados os núcleos temáticos, surgindo as seguintes categorias: conhecimento aparente da patologia; benefícios quanto aos gastos com medicamentos; "mudou muito, porque ela [criança] só vivia internada"; "pratica esporte e não se cansa mais".

\section{Conhecimento aparente da patologia}

Quando perguntadas acerca do entendimento materno quanto à patologia, percebeu-se o conhecimento da patologia como complicada, difícil de ser tratada, com a possibilidade de não ter cura.

"Eu acho que é uma doença dos pulmões e vem mais de família de geração, atinge o coração e deixa a criança sem fôlego e causa cansaço, com essa doença a criança não é saudável [...]" (M02)

"É uma doença que atinge os pulmões e deixa a criança com tosse, cansada. Afeta os pulmões e que pode causar coisas piores, até a morte. Eu já vi uma criança morrer [...]" (M06)

A asma apresenta um profundo impacto na vida da criança, em sua família e na sociedade, constatado pelo grande número de mães de infantes asmáticos recorrendo com frequência aos serviços de saúde em emergência como local rotineiro de consultas, somando-se ao elevado número de internamentos. Esse tipo de atendimento não é considerado adequado, levando a lacunas no tratamento e no controle da patologia ${ }^{(13)}$. O conhecimento aparente da patologia revela diferentes formas de intervenções adequadas ou não para o prognóstico da patologia, causando medo quanto à evolução da enfermidade para o óbito.

\section{Benefícios quanto aos gastos com medicamentos}

Ao indagarmos sobre as mudanças percebidas pelas mães após o filho ser inserido no programa de asma, elegeram-se os relatos que fazem emergir a categoria.

"Melhorou muito, recebo os medicamentos que antes tinha que comprar e agora é de graça, são remédios caros e eu não posso comprar. Antes eu me preocupava muito, passava noites sem dormir quando ele adoecia e agora estou tranquila [...]" (M04)

"Para mim foi muito bom, quando chego aqui no posto com meu filho, recebo os remédios que nem sempre tenho dinheiro para comprar e agradeço muito a Deus por ter conseguido este tratamento de graça e agora melhorou muito [...]" (M09)

A gravidade da apresentação clínica inicial e a resposta ao tratamento com broncodilatadores beta2-agonistas inalatórios definirão qual a indicação para o tratamento da crise asmática. Caso a evolução não seja satisfatória, é encaminhado ao departamento de emergência ou ao prontosocorro. Quanto mais rápido e eficiente ocorrer a intervenção na crise, melhor o desfecho dessa situação clínica, a ponto de se tornar indispensável a abordagem sistematizada e diferenciada pelos serviços de emergência ${ }^{(14)}$.

O tratamento para a criança asmática desponta como de alto custo financeiro para as mães, não correspondendo à renda mensal familiar, o que repercute na qualidade da assistência prestada, incentivando as recidivas das crises. Dessa forma, à disponibilidade dos medicamentos ofertados agrega-se a melhoria da qualidade de vida das famílias acometidas pela patologia.

\section{"Mudou muito, porque ela só vivia internada"}

Os benefícios encontrados, tanto para essas participantes quanto para a criança, principalmente quanto à assistência hospitalar que existia em seu cotidiano durante as crises, são relatados nas falas a seguir:

"Mudou muita coisa, porque eu só vivia no hospital, ele tinha crises muito fortes na madrugada e, depois de participar desse programa de asma aqui no posto, melhorou bastante, então antes eu não conseguia dormir nas crises dele e agora $\operatorname{sim}[\ldots]^{\prime \prime}(\mathrm{M01})$

"Melhorou, porque antes não tinha tranquilidade e agora ele controla as crises, estou bem mais sossegada. E também, não compro mais os medicamentos, que são muito caros [...]" (M10)

A crise asmática abrolha por meio de distintas configurações, que induzem inflamação nas vias aéreas, provocando o broncoespasmo. Os mecanismos que irão desencadear esse processo diferenciam quanto a pessoa, momento, clima, estado emocional e história da doença, cujos agentes que mais contribuem para essas crises são identificados na prática clínica como os alérgenos inalatórios, infecção viral das vias aéreas, poluentes atmosféricos, exercício físico, mudanças climáticas, alimentos, aditivos, drogas e estresse emocional.

\section{"Pratica esporte e não se cansa mais"}

No tocante aos benefícios ressaltados nos filhos, verificou-se, por meio dos relatos, que a prática de esporte se faz presente como um modo de favorecimento à saúde do asmático, evitando as possíveis crises.

"Melhorou, pois só vivia cansada, não dormia direito e não tinha o sono de uma criança saudável. Antes de iniciar o tratamento, só vivia com pneumonia e internada. Então com a educação física mudou muito [...]" (M04)

"Melhorou porque o esporte que ele gosta é o MotoCross, e o pai apoia muito, e ele tava impossibilitado de fazer [...]" (M18)

$A$ atividade física consiste em um dos fatores precipitantes frequentes, sendo a dispneia apresentada durante a prática esportiva. O receio em vivenciá-la é responsável por afastar o asmático da técnica de esportes e das atividades físicas em 
grupo. Assim, ele tende a ser menos ativo, devido às restrições físicas, emocionais e sociais impostas pela doença, gerando estados de depressão, isolamento social, baixa autoestima e falta de motivação ${ }^{(15)}$.

A prática de atividades é imprescindível, pois a criança vivencia o esporte como lúdico, de modo a interferir na saúde física e mental, colocando-a no mesmo nível de qualquer outro infante da mesma idade, repercutindo assim de forma direta na relação social saudável.

\section{CONSIDERAÇÕES FINAIS}

A rotina da díade mãe-filho, que neste serviço recebe orientações de variados profissionais da área da saúde, encaminhamentos para outros serviços e o recebimento dos medicamentos, foi enfatizada. A qualidade do serviço prestado por todos os profissionais de saúde dessa unidade favorece o atendimento da clientela, pois eles dedicam tempo em compreender e auxiliar mães que, ao longo do tratamento dos filhos portadores de asma, surgem necessitando de reuniões em grupo ou até mesmo de uma conversa, orientação individual ou simplesmente de alguns minutos de atenção.

O conhecimento de como a população visualiza o programa de asma, sobretudo pelas orientações fornecidas pelos profissionais de enfermagem que o integram, como exemplo a enfermeira, vislumbra, entre outros aspectos, a promoção e educação da saúde dessa clientela. Destaca-se que as participantes relacionaram que a relevância da assistência da enfermeira na unidade sanitária se encontra correlacionada à função de assessora do médico ao longo da coleta de dados.

Almejou-sebeneficiara pesquisa nocampo de asma, especialmente no atendimento ao cliente infantil, pela dependência do acompanhamento familiar, conscientizando as mães quanto às melhorias encontradas após inserir o filho em um tratamento de asma, por meio de programas que visem a essa assistência.

\section{Referências}

1. Ferrari PF, Rosário FNA, Ribas LFO, Cálice LG. Frequência de asma em

escolares de Curitiba - projeto Isaac (Internacional Study of Asthma and

Allergies in Childhood). J Pediatr. 1998;74(4):299-305.

2. Sociedade Brasileira de Pneumologia e Tisiologia. III Consenso Brasileiro no Manejo da Asma. J Pneumol. 2002.

3. Bettencourt ARC, Oliveira MA, Fernandes ALG. Educação de pacientes com asma: atuação do enfermeiro. J Pneumol. 2002:193-200.

4. Silva LC, Freire LM, Mendes NF, Lopes AC, Cruz A. Carta de Salvador. J

Pneumol. 2002.

5. Ministério da Saúde (BR). Datasus, informaçōes de saúde 2005 [Internet].

[citado em 2008 Set 17]. Disponível em: http://www.datasus.gov.br/.

6. Solé D, Rizzo MCV. Asma aguda na infância. São Paulo: Lemos; 2002.

7. Frota MA, Maia JA, Pereira AS, Nobre CS, Vieira LJES. Reflexão sobre

políticas públicas e estratégias na saúde integral da criança. Enferm Foco. 2010;1(3):89-140.

8. Holanda MA. Asmáticos brasileiros: o tratamento desejado. J Pneumol.

2000;26(3):187-8.

9. Silva CM, coordenador. Asma e rinite: linhas de conduta em atenção básica. Brasília: Ministério da Saúde; 2004.

10. British TS, Scottish IGN. British guideline on the management of asthma. Thorax: BMJ Journal. 2003; 58(Suppl 1):S1-S94.

11. Minayo MCS. Pesquisa social: teoria, método e criatividade. $28^{\mathrm{a}}$ ed. Petrópolis: Vozes; 2010.

12. Ministério da Saúde (BR). Conselho Nacional de Saúde. Resolução $n^{\circ}$ 196 de 10 de Out/196. Diretrizes e normas regulamentadoras de pesquisa envolvendo seres humanos. Brasília: Ministério da Saúde; 1996.

13. Chatkin M, Menezes AMB, Albernaz E, Victora CG, Barros FC. Fatores de

risco para consultas em pronto-socorro por crianças asmáticas no sul do

Brasil. Rev Saúde Pública. 2000.

14. Dalcin PTR, Perin C. Manejo da asma aguda em adultos na sala de

emergência: evidências atuais. AMB Rev Assoc Med Bras. 2009.

15. Gonçalves RC, Nunes MPT, Cukier A, Stelmach R, Martins MA. Carvalho

CRF. Efeito de um programa de condicionamento físico aeróbio nos

aspectos psicossociais, na qualidade de vida, nos sintomas e no óxido

nítrico exalado de portadores de asma persistente moderada ou grave. Rev

Bras Fisioter. 2008. 